\title{
The Psychosocial Impact of Compounding Humanitarian Crises Caused by War and COVID-19 Informing Future Disaster Response
}

\author{
Hakob Harutyunyan, MD; ${ }^{1}$ Artak Mukhaelyan, MD; ${ }^{2}$ Attila J. Hertelendy, $\mathrm{PhD} ;{ }^{3} \odot$ Amalia Voskanyan, \\ $\mathrm{RN} ;{ }^{3}$ Todd Benham, PsyD; ${ }^{3}$ () Fadi Issa, MD; ${ }^{3}$ Alex Hart, MD; ${ }^{3}$ Gregory R. Ciottone, MD ${ }^{3,4}$
}

1. Department of General and Invasive Cardiology, Yerevan State Medical University, Yerevan, Armenia

2. Armavir Medical Center, Armenia

3. Department of Emergency Medicine, Beth Israel Deaconess Medical Center, Boston, Massachusetts, USA

4. Harvard Medical School, Boston, Massachusetts, USA

Correspondence:

Attila J. Hertelendy, $\mathrm{PhD}$

Co-Director of Research

Beth Israel Deaconess Medical Center One Deaconess Rd, Rosenberg Bldg, 2nd Floor

Boston, Massachusetts 02215, USA

E-mail: ahertele@bidmc.harvard.edu

Conflicts of interest/funding: none

Keywords: Armenia; COVID-19; humanitarian crisis; pandemic; war

Abbreviations:

COVID-19: coronavirus disease 2019

ICU: intensive care unit

Received: June 28, 2021

Accepted: July 10, 2021

\section{doi:10.1017/S1049023X21000844}

(C) The Author(s), 2021. Published by

Cambridge University Press on behalf of the

World Association for Disaster and Emergency Medicine.

\section{Abstract}

The coronavirus disease 2019 (COVID-19) pandemic has caused the greatest global loss of life and economic impact due to a respiratory virus since the 1918 influenza pandemic. While health care systems around the world faced the enormous challenges of managing COVID-19 patients, health care workers in the Republic of Armenia were further tasked with caring for the surge of casualties from a concurrent, large-scale war. These compounding events put a much greater strain on the health care system, creating a complex humanitarian crisis that resulted in significant psychosocial consequences for health care workers in Armenia.

Harutyunyan H, Mukhaelyan A, Hertelendy AJ, Voskanyan A, Benham T, Issa F, Hart A, Ciottone GR. The psychosocial impact of compounding humanitarian crises caused by war and COVID-19 informing future disaster response. Prehosp Disaster Med. 2021;36(5):501-502.

The coronavirus disease 2019 (COVID-19) pandemic has caused the greatest global loss of life and economic impact due to a respiratory virus since the 1918 influenza pandemic. While health care systems around the world faced the enormous challenges of managing COVID-19 patients, health care workers in the Republic of Armenia were further tasked with caring for the surge of casualties from a concurrent, large-scale war. ${ }^{1}$ These compounding events put a much greater strain on the health care system, creating a complex humanitarian crisis that resulted in significant psychosocial consequences for health care workers in Armenia. ${ }^{2,3}$

The Nagorno-Karabakh region is a contested territory internationally recognized as part of Azerbaijan, but inhabited and controlled primarily by Armenians. Since the dissolution of the former Soviet Union, there have been two wars and numerous skirmishes over the territory. On September 27, 2020, the "44-day war" began over Nagorno-Karabakh, ultimately claiming approximately 5,000 Armenian lives with many more wounded. ${ }^{4}$ At the onset of the war, there were 70,836 confirmed cases of COVID-19 in Armenia, with 2,484 new cases diagnosed daily. ${ }^{2}$ Of the approximately 150,000 civilians in the contested region, a large percentage were displaced into Armenia following the onset of hostilities. This caused difficulty in determining accurate rates of infection, and also likely led to an increase in cases due to an inability to maintain quarantine and isolation precautions as civilians hastily fled the region. ${ }^{5}$

With only 4.4 doctors per 1,000 population, ${ }^{6}$ the pandemic put an unprecedented and overwhelming burden on Armenian health care workers. In addition to a shortage of physicians, fears of being infected, requirements to self-isolate, substantial workloads, and low wages were added strains on many. Also of consequence and due to need, many of the frontline workers treating COVID-19 patients were young, inexperienced physicians and residents working long hours. Multiple 24-hour shifts per week at the outset of the pandemic were common, and when COVID-19 cases created an additional demand for intensive care unit (ICU) care, working four consecutive nearly 24-hour shifts, with scant time to sleep between, became the norm. Because of these compounding factors, health care workers experienced near-continuous exhaustion and stress, resulting in decreased productivity and putting them at greater risk for psychosocial sequelae.

The influx of casualties from the Nagorno-Karabakh war were superimposed onto this overworked and overwhelmed health care system, creating an unprecedented humanitarian 
crisis. The already severely strained health care workforce was now required to simultaneously engage on two fronts, with many health care workers staffing COVID-19 clinics also working in hospitals that treated war casualties, or assisting in evacuating war casualties between their clinic shifts. As a result, health care workers experienced numerous overwhelming physiological stressors, including sleep deprivation and working while personally infected with COVID-19, an extraordinarily unfortunate indicator of how severely under-staffed the health care system was. Moreover, the psychological impact of treating gruesome war injuries, tending to wounded and dead colleagues, experiencing hospitals and evacuation routes being targeted by enemy artillery and drone attacks, while concurrently working with severely ill COVID-19 patients with poor prognoses, resulted in early and significant psychosocial consequences for many.

Unfortunately, during the war, international humanitarian awareness and response was delayed by a combination of geopolitics and an on-going global health emergency. This delay resulted in prolonged health care worker exposure to these stressful conditions, and may have exacerbated the psychosocial impact through a perceived global indifference to the crisis. There has also not been a comprehensive after-action analysis on the psychosocial impact of this compounded humanitarian disaster, the magnitude of which can be glimpsed through firsthand accounts such as this:

My last day in Nagorno-Karabakh was November 7, 2020 when I transported five wounded soldiers in one ambulance on a six-hour, over 300kilometer evacuation to the trauma hospital in Yerevan Armenia. The following morning, I started a new workday treating COVID-19 patients. Hakob Harutyunyan, $M D$

It is well-known that the cumulative impact of disasters can put people at greater risk for psychosocial sequelae. ${ }^{7,8}$ We believe there are valuable lessons to be learned from this only active war that occurred during the COVID-19 pandemic, to date. We propose local mental health capacity be enhanced in the form of rapid response teams to ensure that health care workers are able to maintain their resilience in the face of complex disasters, and to advise leaders on how to promote responder well-being in adverse situations. In addition, an in-depth after-action review should be done following complex disasters to examine what systematic failures could have been prevented to minimize these psychosocial stressors in similar future events.

\section{References}

1. Knipper P, Bégué T, Pasquesoone L, et al. [Plastic surgery and fighting: our experience during Nagorno-Karabakh war in 2020]. Ann ChirPlastEsthet. 2021;66(3): 201-209.

2. Kazaryan AM, Edwin B, Darzi A, et al; Doctors Against The War collaborators. War in the time of COVID-19: humanitarian catastrophe in Nagorno-Karabakh and Armenia. Lancet Glob Health. 2021;9(3):e243-e244.

3. Markosian C, Layne CM, Petrosyan V, Shekherdimian S, Kennedy CA, Khachadourian V. War in the COVID-19 era: mental health concerns in Armenia and Nagorno-Karabakh. Int J Soc Psychiatry. 2021. Epub ahead of print.

4. Losh J. Armenia Buries Its Dead but Can't Put to Rest the Horrors of Recent War. Foreign Policy News. https://foreignpolicy.com/2021/01/06/armenia-loss-nagornokarabakh-azerbaijan-horrors-of-war/. Accessed January 2021.
5. Avedian L. Fighting on To Fronts. The Armenian Weekly. https://armenianweekly.com/ 2021/01/14/fighting-on-two-fronts/. Accessed January 2021.

6. World Health Organization Global Health Observatory. Medical Doctors per 10,000 Population. https://www.who.int/data/gho/data/indicators/indicator-details/GHO/ medical-doctors-(per-10-000-population)?bookmarkId=9368a903-a573-47d9-b63ffa2789bd3a96. Accessed January 2021.

7. Lowe SR, McGrath JA, Young MN, et al. Cumulative disaster exposure and mental and physical health symptoms among a large sample of Gulf Coast residents. J Trauma Stress. 2019;32(2):196-205.

8. Harville EW, Shankar A, Dunkel Schetter C, Lichtveld M. Cumulative effects of the Gulf oil spill and other disasters on mental health among reproductive-aged women: the Gulf resilience on women's health study. Psychol Trauma. 2018;10(5):533-541. 